DOI: 10.4274/tpa.125

\title{
Familial facial palsy
}

\author{
Barış Ekici, Burak Tatll, Meral Özmen \\ Istanbul University Medical Faculty Department of Pediatrics, Division of Pediatric Neurology, Istanbul, Turkey
}

\section{Summary}

Facial palsy is a sporadic disease related to cold exposure, infections and psychogenic factors. In this case report, we present a 14-year old boy with familial facial palsy. Rarely, familial cases have been reported. Risk of recurrence is increased in familial cases. Sporadic and familial cases must be treated with the same approach. (Turk Arch Ped 2012; 47: 67-9)

Key words: Bell's palsy, facial palsy, familial

\section{Introduction}

More than half of facial palsy cases occur as a result of involvement of the peripheral nerve. The prevelance of this picture which was described in 1829 by Dr. Charles Bell for the first time is reported to be $10-30 / 100000$. The disease is specifically observed with a higher rate between the ages of 15 and $45(1,2)$. There are studies which reported that peripheral facial palsy is increased in winter months with the effect of cold weather $(3,4)$.

Peripheral facial palsy is a condition in which usually one side of the face is involved and which is accompanied by a previous viral infection. In $2,4-28,6 \%$ of the patients, a history of disease is reported to be present in a relative (5). Idiopathic facial palsy families have been reported rarely. The disease is thought to have autosomal dominant heritage which does not show complete transition in these families (6-8).

In this article, a case who presented with peripheral facial palsy and his familial history is presented.

\section{Case}

A 14-year old male patient presented with complaints including weakness in the left side of the face, inability to close the left eyelid and sliding of the mouth to the right side while laughing which started 3 months ago. The patient was given oral vitamin B complex and physical therapy was applied for 15 days. The patient had no history of infection or drug usage before facial palsy. In his familial history, it was learned that his older sister had right facial palsy at the age of 10 and left facial palsy at the age of 14 , his mother's aunt had left peripheral facial palsy at the age of 52 and his mother's grandmother had unilateral facial palsy at her 30's.

On physical examination, it was found that the patient could not lift his left eyebrow completely, could not close his eyelid, the nasolabial line was erased and the mouth slided to the right side when he was asked to show his teeth (Picture 1 and 2). His sensory evaluation was natural. These findings were compatible with House-Brackmann classification grade III. His blood pressure was measured to be $115 / 75 \mathrm{mmHg}$. Other neurological and systemic examinations were normal.

Cranial magnetic resonance imaging was found to be within normal limits. Electromyography revealed partial involvement in the left facial nerve. In the tympanogram test, ipsilateral and contralateral reflex response could not be obtained in the left ear.

\section{Discussion}

Idiopathic facial palsy families have been reported rarely and mostly autosomal dominant heritage has been emphasized $(6,8)$. When the family tree of our patient was examined, it was recognized that three of four generations were affected and the heritage was carried by the maternal side. Considering that the family involved no consanguineous marriages, autosomal dominant inheritage and incomplete 


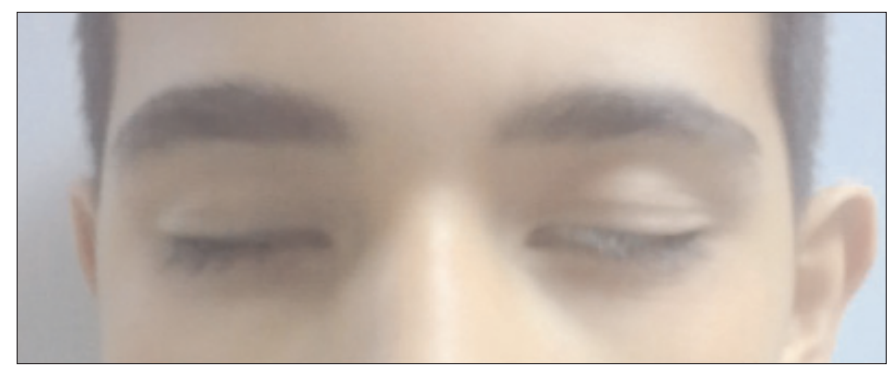

Picture 1. The patient can not close his left eye completely

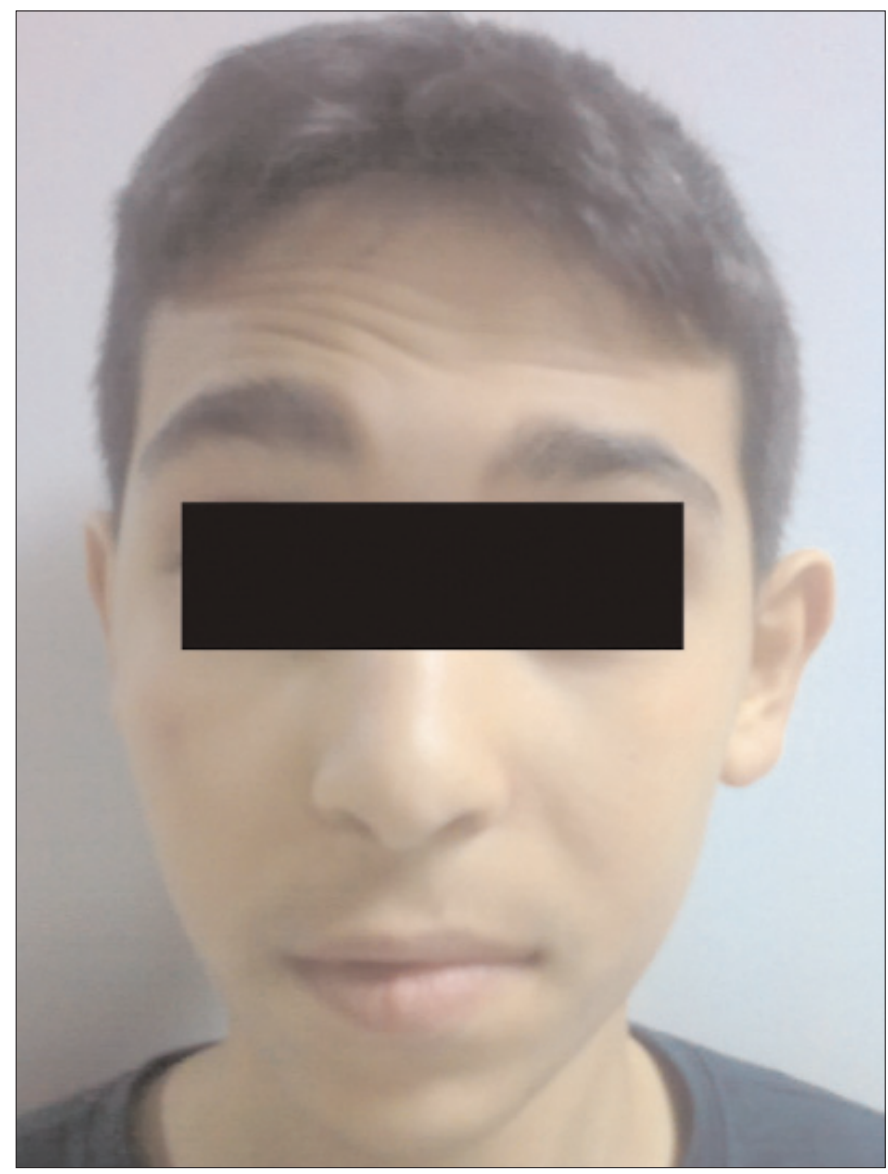

Picture 2. The patient can not lift his left eyebrow completely and can not wrinkle his forehead.

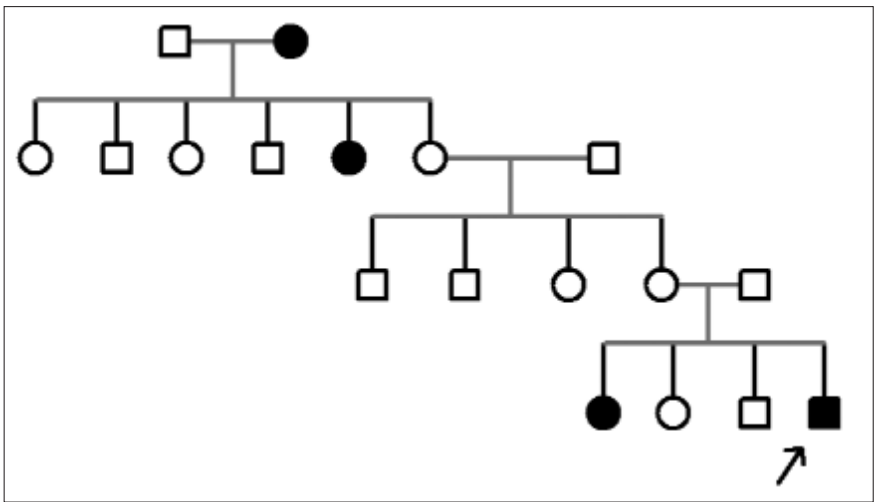

Figure 1. Family tree transition were considered because the patient's mother and siblings were not affected and there was generation skip.

Although the fact that the patient presented approximately 3 months after facial palsy first appeared and did not improve completely suggested the possibility that familial facial palsy may have a poorer prognosis, variable prognosis has been reported in the literature $(5,8)$. History of complete improvement in the other cases in the family supported this. The patient's older sister had a history of facial palsy at the ages of 10 and 14 in different sides. It was reported that the possibility of recurrence of familial idiopathic facial palsy is inceased, when it occurs during childhood for the first time (9).

Peripheral facial palsy has been associated with trigerring factors including mood changes or infection. Latent infection related to herpes virus has been blamed in the etiology $(10,11)$. No distinct triggering factor was found in our case. The relation of idiopathic familial facial palsy with these factors is not known.

The recommendation of the American Neurology Academy in 2001 (12) is administration of $1 \mathrm{mg} / \mathrm{kg}$ prednisolone for 10 days in the early period in idiopathic facial palsy. The efficiency of acyclovir in a few cases is controversial. Since the number of familial cases is low and clinical experience is not sufficient, there is no treatment approach on which a consensus has been established. We believe that the same treatment approach should be adopted in these patients. Since our patient presented at a late period, there was no need for steroid treatment.

In the monosymptomatic form of Melkersson-Rosenthal syndrome which proceeds only with familial facial palsy and has a similar inheritance, surgical decompression of the facial nevre has been reported, but no surgical intervention is recommended in idiopathic cases (13).

Positive familial history in patients presenting because of peripheral facial palsy should suggest the possibility of recurrence in the follow-up. For treatment of familial idiopathic facial palsy the same approach as for sporadic cases should be adopted.

\section{References}

1. Pavlou E, Gkampeta A, Arampatzi M. Facial nerve palsy in childhood. Brain Dev 2011; 33: 644-50.

2. Bleicher JN, Hamiel S, Gengler JS, Antimarino J. A survey of facial paralysis: etiology and incidence. Ear Throat Nose J 1996; 75: 355-7.

3. Campbell KE, Brundage JF. Effects of climate, latitude and season on the incidence of Bell's palsy in the US armed forces, October 1997 to September 1999. Am J Epidemiol 2002; 156: 32-9.

4. Mair IW, de Graff AS. Peripheral facial palsy in subarctic Norway. Acta Otolaryngol 1974; 77: 119-25.

5. Clement WA, White A. Idiopathic familial facial nerve paralysis. $J$ Laryngol Otol 2000; 114: 132-4.

6. Qin D, Ouyang Z, Luo W. Familial recurrent Bell's palsy. Neurol India 2009; 57: 783-4.

7. Triantafyllou NI, Kararizou E, Gkiatas K. Familial aggregation of Bell's palsy. Balkan Mil Med Rev 2007; 10: 11-2.

8. Amit R. Famial juvenile onset of Bell's palsy. Eur J Pediatr 1987; 146: 608-9. 
9. Takahashi A, Fujiwara R. Familial Bell's palsy- report of seven families. Clin Neurol 1971; 11: 454-61.

10. Kuhn MA, Nayak S, Camarena V, et al. A cell culture model of facial palsy resulting from reactivation of latent herpes simplex type 1. Otol Neurotol 2012; 33: 87-92.

11. Schirm J, Mulkene PS. Bell's palsy and herpes simplex virus. APMIS 1997; 105: 815-23.
12. Grogan PM, Gronseth GS. Practice parameter: steroids, acyclovir, and surgery for Bell's palsy (an evidence-based review): Report of the Quality Standards Subcommittee of the American Academy of Neurology. Neurology 2001; 32: 945-61.

13. Graham MD, Kemink JL. Total facial nerve decompression in recurrent facial paralysis and the Melkersson-Rosenthal syndrome: a preliminary report. Am J Otol 1986; 7: 34-7. 